\title{
Review and Scientometric Analysis of IEEE 37 Radial Feeder Publications
}

\author{
Jagdish Prasad Sharma ${ }^{1}$, H. Ravishankar Kamath ${ }^{2}$ \\ Research Scholar, Mewar University, Chittorgarh, India ${ }^{1}$ \\ Malwa Institute of Technology, Indore, India ${ }^{2}$
}

\begin{abstract}
In this paper, a review and scientometric analysis of IEEE 37 Radial Feeder publications is carried out to find out literature growth and researcher interest. An IEEE 37 Radial feeder is a rare, highly unbalance underground feeder in delta configuration and located in California. The publication of study is obtained from IEEE Xplore and Science direct digital library. It is observed that the IEEE Xplore digital library has total 34 publications during 1995 to 2015, while Science direct digital library has only 05 during 2008 to 2015. All these papers are discussed in the literature review. In IEEE Xplore direct digital library, maximum publication on this topic appeared in during 2014 and whereas Science direct digital library have only 01 publications for same. Authors from the USA have contributed the maximum as compared with other countries. In the IEEE Xplore digital library, the relative growth rates (RGR) have continuously decreased from 2003 (0.693) to 2011 (0.095) and maximum doubling time (DT) occurred in 2015 (11.431), while in science direct digital library RGR has continuously decreased from 2011 (0.693) and DT has increased from 1.709 to 3.106 during last three years.
\end{abstract}

Keywords: IEEE 37 feeder; scientometric analysis; relative growth rate; doubling time.

\section{INTRODUCTION}

Deregulation of electrical utilities has accelerated to run their distribution feeder at high efficiency with the least possible expenditure. Unbalanced distribution feeder contributes to higher power loss due to low operating voltage, high current and theft and privileges. To keep these losses in limits following assignments is required.

- Determine characteristics of existing feeder.

- Effective and efficient computational tools to analyze technical loss.

- Determination of the high loss prone area and plan to reduce Aggregated Technical \& Commercial (AT\&C) losses within permissible limits.

Technological innovations have led a path to the utility to analyze their existing feeder before purchasing expensive electrical equipment using digital computer software, which are used to determine the optimal sizing of DG and performance scenarios. A digital computer is a paramount importance to analyze unbalanced three-phase radial distribution feeders. In this chapter, an attempt is made to review one or more issues, which are pertinent to this thesis. Apart from above a scientometric analysis of IEEE 37 Radial Feeder publications are carried out to find out literature growth and researcher interest.

An IEEE 37 feeder is considered as a benchmark test feeder due to unbalanced characteristics and load flow converges problem.

It is a rare underground feeder connected in a delta configuration. All loads have a composition of constant PQ, constant current and constant impedance. Researchers have taken up this feeder for the power flow algorithm, distributed generation, smart grid, and optimization and reconfiguration problem. Maximum researches were carried out for distributed generation problem and smart grid problem holds the second position.
All published work in IEEE Xplore and science direct digital library are studied and considered for scientometric analysis.

\section{RELATED WORK}

A load flow convergence problem is solved using sensitivity matrix and Kron reduction techniques and results are demonstrated on IEEE 37 and IEEE 123 node test feeder [1]. A real-time probabilistic load flow (PLF) with the help of Monte Carlo simulation (MCS) proposed and exploit inherent patterns of the load flow model with SPIRAL code generator[2,3].A globally convergent trustregion method for power flow algorithm is proposed by Abdelaziz, M.M.A. et al.[4].

The design of load following controller for micro turbines suggested using particle swarm optimization technique [5].Symmetrical components based on three phase power flow algorithms using multi-core processors parallel programming proposed and tested on IEEE 13, 34 and 123 node feeder and a practical 37 node distribution feeder [6]. A novel procedure has been proposed to estimate bus voltages and power losses on distribution feeders which were based on simulated annealing [7].Medina, M.M. et al., developed a three-phase algorithm for shipboard power systems (SPS) considering issues of multiple sources, ring configuration, and radial load flow [8].

Newton-Raphson based improved unbalance load flow[9] proposed and tested upon the IEEE test systems consisting of $4,13,34,37$, and 123. Impact of DG penetration on system losses and voltage deviation for load increment is increasing studied [10] For optimal placement and sizing of distributed generators on balanced/ unbalanced distribution networks, big bang big crunch optimization algorithm proposed by Hegazy Y.G.et al.[11], whereas a 
particle swarm optimization-based methodology for An algorithm for optimal scheduling of energy storage optimal sizing and placement of distributed generation is system to minimize feeder loss is proposed using proposed for unbalanced reactive power support by Reddy Lagrange multipliers [32] and impact of EVs on the et al. [12].Optimal placement and the sizing problem of distribution network IEEE-37 Node Test Feeder in the the voltage controlled distributed generators is solved presence of various load types is checked[33].

using big bang-big crunch method [13]. Dong-Jun Won et al., determined the optimal number of power quality monitors and their locations [14]. An asymptotic consensus approach to coordinate a set of DG units for collective and certain reference reactive power adopted [15].Zhipeng Liu et al., has proposed a month Carlo simulation based approach to solve optimal siting and sizing of distributed generators considering uncertainties [16].Dynamic analysis of distribution feeders using differential algebraic equations (DAE) and theimpact of large PV generators on the existing distribution feeders analyzed [17].Ramesh, L. et al., introduced a new technique to minimize power losses and improves voltage stability using the optimum DG model in terms of size, location and operating point of DG through sensitivity analysis [18]. An artificial neural network models presented to represent type-3 doubly-fed induction generator and type-4 permanent magnet synchronous generator [19], whereas an integration of wind generator (WG) model for unbalanced systems proposed with commercial software packages such as PSS®E and PSS@SINCAL [20].

Reactive power support and power loss minimization for unbalanced power distribution systems proposed and performance validated on modified IEEE 37 node test feeder [21]. Hoff, T. and Shugar and D.S. described a way to optimize plant size, plant location along a distribution feeder and calculated the electrical line loss reduction through the use of grid-support photovoltaic [22].Ziari, I. et al., optimized the placement and sizing of distributed generators (DG) using a combination of discrete particle swarm optimization and genetic algorithm [23].An objective function consists of the distribution line loss cost and the capacitor's investment cost optimized by an iteratively based strategy [24].An improvement in voltage profile and system loss showed with integration of DG into the distribution network [25].

Stochastic characteristics of wind power, photovoltaic power, and system demand incorporated for optimal placement of dispatchable distributed generation using Big Bang-Big crunch method [26]. The impact of both SVR and high penetration of PQ and PV distributed generation (DG) model on voltage profile and system power losses also studied [27].Naiem, A.F. et al., introduced a recloser fuse coordination approach to check the fault condition [28] and Baldwin, T. et al., has demonstrated fault location by processing the combined fault current and voltage data recorded at the advanced metering infrastructure (AMI) [29]. A novel formulation for state estimation of the distribution system with a reduced considerable size of state variables of demands and generators proposed for large-scale distribution grids [30]. Wencong $\mathrm{Su}$ et al., formulated a stochastic problem energy scheduling of micro grid and discussed challenges for integration of plug-in electric vehicles, micro gas turbines and diesel generators, and battery banks[31].

A control algorithm to reduce the capacity of a previously proposed smart charger for electric vehicles simulated using PSIM software. Results showed a reduction in the smart charge capacity by controlling reactive power at source side [34]. Wencong Su et al., modeled predictive control based power dispatch for distribution system considering an electric vehicle (EV) uncertainty. Charging time, initial battery state-of-charge and start/end time has been considered as uncertain parameters [35].

A sparsity-tuning parameter adjustment employed for reconfiguration of distribution system by changing the non-convex system into the convex system by adjusting a sparsity-tuning parameter, whereas semidefinite relaxation techniques along with sparsity-promoting regularization are used for operation cost of DG[36,39].A graph-theoretic distribution system restoration (DSR) strategy to maximize the restored load and minimizes the number of switching operations proposed by Juan Li et al[37].

Khushalani, S. et al., has discussed a procedure for evaluating the impact of the site and size on both the original distribution power system and a reconfigured power system after a fault [38].

\section{SCIENTOMETRIC ANALYSIS}

The aim of scientometric analysis is to avoid duplication in research subject. The following objectives are considered for this analysis.

Growth of literature on research \& development on IEEE 37 feeder.

- Find the scattering of literature based on publication types and analyze country-wise contributions of the publications.

An IEEE 37 Radial feeder is rare, highly unbalance underground feeder in delta configuration and located in California. The publication of study is obtained from IEEE Xplore and Science direct digital library. It is observed that the IEEE Xplore digital library has total 34 publications during 1995 to 2015 while Science direct digital library has only 05 during 2008 to 2015. All these papers are discussed in the literature review. In IEEE Xplore direct digital library, maximum publication on this topic appeared in during 2014 and whereas Science direct digital library has only 01 publications for same. Authors from the USA have contributed the maximum as compared with other countries. In the IEEE Xplore digital library, the relative growth rates (RGR) have continuously decreased from 2003 (0.693) to 2011 (0.095) and maximum doubling time (DT) occurred in 2015 (11.431), while in science direct digital library RGR has continuously decreased from 2011 (0.693) and DT has increased from 1.709 to 3.106 during last three years. The source of publications covered by IEEE Xplore digital and science direct digital library on said topic is mentioned in below Table I. 
INTERNATIONAL JOURNAL OF INNOVATIVE RESEARCH IN ELECTRICAL, ELECTRONICS, INSTRUMENTATION AND CONTROL ENGINEERING Vol. 4, Issue 2, February 2016

TABLE I PUBLICATIONS OUTPUT AND TYPE

\begin{tabular}{|l|l|c|c|}
\hline $\begin{array}{l}\text { S. } \\
\text { No. }\end{array}$ & $\begin{array}{l}\text { Forms of } \\
\text { publications }\end{array}$ & $\begin{array}{l}\text { IEEE - } \\
\text { No(\%) }\end{array}$ & $\begin{array}{l}\text { Science } \\
\text { direct No(\%) }\end{array}$ \\
\hline 1 & $\begin{array}{l}\text { Conference } \\
\text { Publications }\end{array}$ & $\begin{array}{c}24 \\
(61.54 \%)\end{array}$ & 0 \\
\hline 2 & $\begin{array}{l}\text { Journal \& } \\
\text { Magazine articles }\end{array}$ & $\begin{array}{c}8 \\
(20.51 \%)\end{array}$ & $\begin{array}{c}5 \\
(12.82 \%)\end{array}$ \\
\hline 3 & $\begin{array}{l}\text { Early Access } \\
\text { Articles }\end{array}$ & $2(5.14 \%)$ & 0 \\
\hline
\end{tabular}

A. Relative Growth Rate and Doubling Time for IEEE digital library Publications

During the period of 1995 to 2015 , a total of 34 publications on said topic was published in IEEE Xplore digital library and highest 09 publications in 2014. The Relative Growth Rate (RGR) is the increase in the number of articles or pages per unit of time [40]. If the number of articles or pages of a subject doubles during a specified period, which is resulting in the difference between the logarithms of numbers at the commencement and finish instance of this period at logarithm of the number 2 . Accordingly, corresponding doubling time (DT) for each specific period of an interval is computed [40].

TABLE III RELATIVE GROWTH RATE (RGR) AND DOUBLING TIME (DT)

\begin{tabular}{|l|l|l|l|l|l|l|}
\hline Year & $\begin{array}{l}\text { No. of } \\
\text { public } \\
\text { ations }\end{array}$ & $\begin{array}{c}\text { Cumu } \\
\text {-lative } \\
\text { Total }\end{array}$ & $\begin{array}{c}\text { Loge } \\
\text { W1 }\end{array}$ & $\begin{array}{c}\text { Loge } \\
\text { W2 }\end{array}$ & RGR & DT \\
\hline 1995 & 1 & 1 & & 0 & & \\
\hline 2003 & 1 & 2 & 0 & 0.693 & 0.693 & 0.999 \\
\hline 2005 & 2 & 4 & 0.693 & 1.386 & 0.693 & 0.999 \\
\hline 2007 & 1 & 5 & 1.386 & 1.609 & 0.223 & 3.106 \\
\hline 2008 & 3 & 8 & 1.609 & 2.079 & 0.470 & 1.474 \\
\hline 2009 & 1 & 9 & 2.079 & 2.197 & 0.118 & 5.884 \\
\hline 2010 & 1 & 10 & 2.197 & 2.302 & 0.105 & 6.577 \\
\hline 2011 & 1 & 11 & 2.302 & 2.398 & 0.095 & 7.271 \\
\hline 2012 & 7 & 18 & 2.398 & 2.890 & 0.492 & 1.407 \\
\hline 2013 & 5 & 23 & 2.890 & 3.135 & 0.245 & 2.827 \\
\hline 2014 & 9 & 32 & 3.135 & 3.466 & 0.330 & 2.099 \\
\hline 2015 & 2 & 34 & 3.466 & 3.527 & 0.060 & 11.43 \\
\hline
\end{tabular}

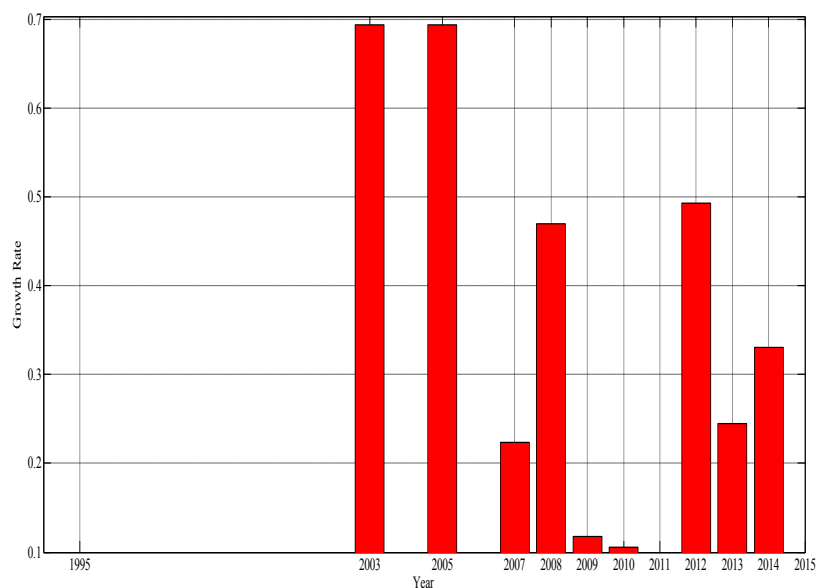

Fig. 1Relative growth rate for publication in IEEE Xplore digital library

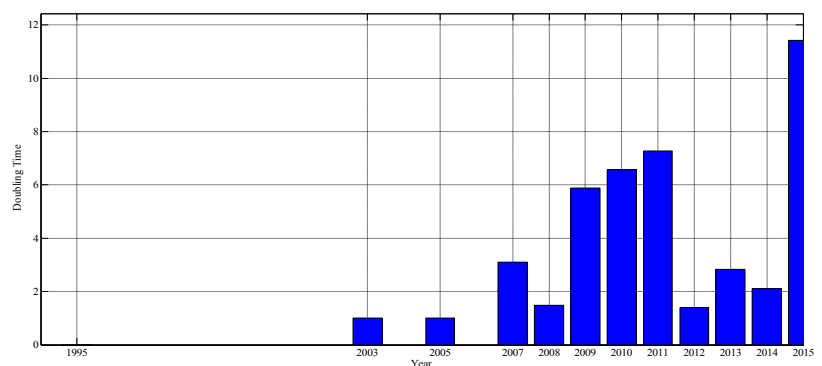

Fig. 2Doubling time for publication in IEEE Xplore digital library

It has been observed from Figure 1, Figure 2 and Table II that the RGR has continuously decreased from 2003 (0.693) to $2011(0.095)$ and maximum DT occurred in 2015 (11.431).

A total of 05 publications on said topic were published in science direct digital library during the period from 2008 to 2015 and maximum 01 publications appeared in science direct digital library and none publication in 2009,2010 and 2012.

\section{TABLE IIIII RELATIVE GROWTH RATE (RGR) AND DOUBLING TIME (DT)}

\begin{tabular}{|l|l|l|l|l|l|l|}
\hline Year & $\begin{array}{l}\text { No. of } \\
\text { public } \\
\text { ations }\end{array}$ & $\begin{array}{l}\text { Cumu } \\
\text { l-ative } \\
\text { Total }\end{array}$ & $\begin{array}{l}\text { Loge } \\
\text { W1 }\end{array}$ & $\begin{array}{l}\text { Loge } \\
\text { W2 }\end{array}$ & RGR & DT \\
\hline 2008 & 1 & 1 & & 0 & & \\
\hline 2009 & 0 & 1 & 0 & 0 & 0 & - \\
\hline 2010 & 0 & 1 & 0 & 0 & 0 & - \\
\hline 2011 & 1 & 2 & 0 & 0.693 & 0.693 & 1 \\
\hline 2012 & 0 & 2 & 0.693 & 0.693 & 0.000 & - \\
\hline 2013 & 1 & 3 & 0.693 & 1.099 & 0.405 & 1.71 \\
\hline 2014 & 1 & 4 & 1.099 & 1.386 & 0.288 & 2.41 \\
\hline 2015 & 1 & 5 & 1.386 & 1.609 & 0.223 & 3.11 \\
\hline
\end{tabular}

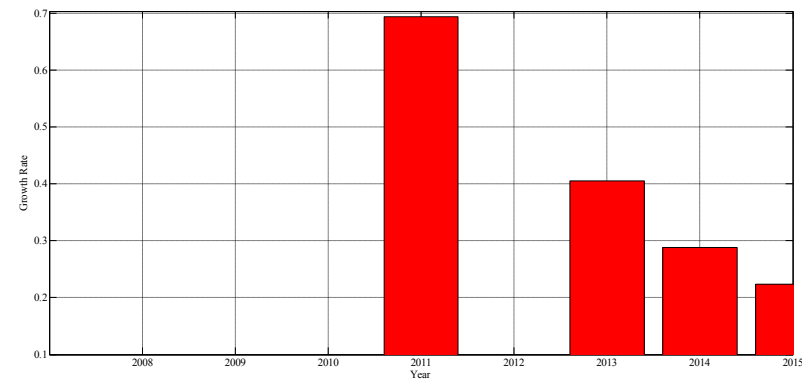

Fig. 3Relative growth rate for publication in science direct digital library

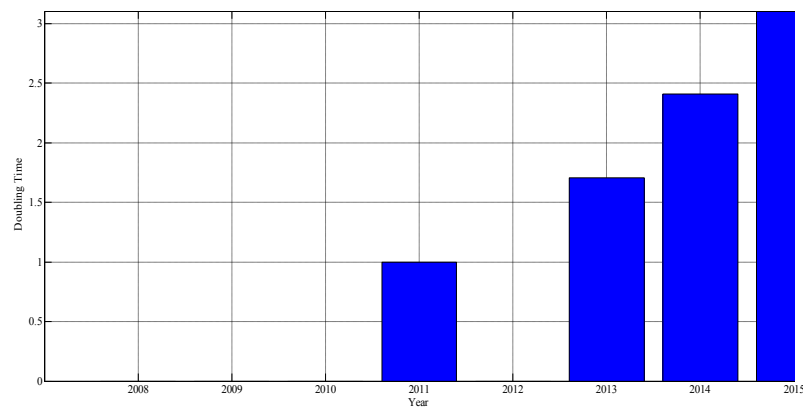

Fig. 4Doubling time for publication in science direct digital library 
It has been observed from Table III and Figure 3, that the RGR has continuously decreased from 2011 (0.693).DT has increased from 1.709 to 3.106 during last three years as shown in Figure 4.

\section{B. Geographical Distribution of Publications}

In the IEEE Xplore digital library, 13 known countries involved in carrying out research in said area. Geographical distribution of publications on IEEE feeder is detailed in Table IV and it found the USA ranked first and for 07 publications country details are not available.

\section{TABLE IVV RELATIVE GROWTH RATE (RGR) AND DOUBLING TIME (DT)}

\begin{tabular}{|l|l|l|l|}
\hline Year & Country & No of articles & No.of articles (\%) \\
\hline 1 & Australia & 1 & $2.94 \%$ \\
\hline 2 & Brazil & 1 & $2.94 \%$ \\
\hline 3 & Canada & 2 & $5.88 \%$ \\
\hline 4 & China & 1 & $2.94 \%$ \\
\hline 5 & Colombia & 1 & $2.94 \%$ \\
\hline 6 & Egypt & 2 & $5.88 \%$ \\
\hline 7 & India & 2 & $5.88 \%$ \\
\hline 8 & Japan & 1 & $2.94 \%$ \\
\hline 9 & Malaysia & 1 & $2.94 \%$ \\
\hline 10 & Padang & 1 & $2.94 \%$ \\
\hline 11 & Seattle & 1 & $2.94 \%$ \\
\hline 12 & USA & 12 & $35.29 \%$ \\
\hline 13 & Venezuela & 1 & $2.94 \%$ \\
\hline
\end{tabular}

\section{CONCLUSION}

A review study and scientometric analysis for IEEE 37 feeder related publications available on by IEEE Xplore library and science direct digital library. During review study, it is observed that 20 authors publish research work on IEEE 37 feeder with distributed generation while 08 authors had developed a power flow algorithm for analysis of same feeder and 06 authors published research work associated with a smart grid on IEEE 37 feeder. Relative growth rate reveals that publications on IEEE 37 feeder are continually decreased. A possible reason may be the load flow convergence problem with this feeder. Total 24 articles out of 39 were only published in IEEE conference and all 05 publications reported in journals of science direct digital library. This shows that authors are more interested in the journal article in science direct, which is giving hope for more literature on this subject.

\section{REFERENCES}

[1] Hongbo Sun; DUBEY, A.; Nikovski, D.; Ohno, T.; Takano, T.; Kojima, Y., "Decoupled three-phase load flow method for unbalanced distribution systems," Power System Technology (POWERCON), 2012 IEEE International Conference on , vol., no., pp.1,6, Oct. 30 2012-Nov. 22012 doi: 10.1109/PowerCon.2012.64 01263

[2] Tao Cui; Franchetti, F., "A multi-core high performance computing framework for probabilistic solutions of distribution systems," Power and Energy Society General Meeting, 2012 IEEE, vol., no., pp.1,6, 22-26 July 2012 doi: 10.1109/PESGM.2012.6344987

[3] Tao Cui; Franchetti, F., "Optimized parallel distribution load flow solver on commodity multi-core CPU," High Performance Extreme Computing (HPEC), 2012 IEEE Conference on , vol., no., pp.1,6, 10-12 Sept. 2012 doi: 10.1109/HPEC.2012.6408675

[4] Abdelaziz, M.M.A.; Farag, H.E.; El-Saadany, E.F.; Mohamed, Y.A.-R.I., "A globally convergent trust-region method for power flow studies in active distribution systems," Power and Energy
Society General Meeting, 2012 IEEE , vol., no., pp.1,7, 22-26 July 2012 doi: 10.1109/PESGM.2012.6344971

[5] Al-Hinai, A.; Feliachi, A., "Microturbines load following controller design in deregulated power distribution systems," Power and Energy Society General Meeting - Conversion and Delivery of Electrical Energy in the 21st Century, 2008 IEEE , vol., no., pp.1,6, 20-24 July 2008 doi: 10.1109/PES.2008.4596632

[6] Ghazali, S.; Nor, K.M.; Abdel-Akher, M., "," TENCON 2009 - 2009 IEEE Region 10 Conference, vol., no., pp.1,6, 23-26 Jan. 2009 doi: 10.1109/TENCON.2009.5395901

[7] De Souza, Benemar A.; Sousa, Andrea A., "State estimation of distribution network using simulated annealig," Electricity Distribution, 2005. CIRED 2005. 18th International Conference and Exhibition on , vol., no., pp.1,4, 6-9 June 2005

[8] Medina, M.M.; Qi, L.; Butler-Purry, K.L., "A three phase load flow algorithm for shipboard power systems (SPS)," Transmission and Distribution Conference and Exposition, 2003 IEEE PES , vol.1, no., pp.227,233 Vol.1, 7-12 Sept. 2003 doi: 10.1109/TDC.2003.13 35220

[9] Sameni, A.; Nassif, A.B.; Opathella, C.; Venkatesh, B., "A modified Newton-Raphson method for unbalanced distribution systems," Smart Grid Engineering (SGE), 2012 IEEE International Conference on , vol., no., pp.1,7, 27-29 Aug. 2012 doi: 10.1109/SGE.2012.6463955

[10] Sujatha Kotamarty, Sarika Khushalani, Noel Schulz, Impact of distributed generation on distribution contingency analysis, Electric Power Systems Research, Volume 78, Issue 9, September 2008, Pages 1537-1545, ISSN 0378-7796, http://dx.doi.org/10.1016/ j.epsr.2008 .01.020

[11] Hegazy, Y.G.; Othman, M.M.; El-Khattam, W.; Abdelaziz, A.Y., "Optimal sizing and siting of distributed generators using Big Bang Big Crunch method," Power Engineering doi: 10.1109/UPEC.2014.6934787Conference (UPEC), 2014 49th International Universities, vol., no., pp.1,6, 2-5 Sept. 2014

[12] [5] Reddy, S.S.; Dey, S.H.N.; Paul, S., "Optimal size and location of Distributed Generation and KVAR support in unbalanced 3- $\Phi$ distribution system using PSO," Emerging Trends in doi: 10.1109/ICETEEEM.2012.6494447Electrical Engineering and Energy Management (ICETEEEM), 2012 International Conference on , vol., no., pp.77,83, 13-15 Dec. 2012

[13] Othman, M.M.; El-Khattam, W.; Hegazy, Y.G.; Abdelaziz, A.Y., "Optimal Placement and Sizing of Distributed Generators in Unbalanced Distribution Systems Using Supervised doi: 10.1109/TPWRS.2014.2331364Big Bang-Big Crunch Method," Power Systems, IEEE Transactions on , vol.30, no.2, pp.911,919, March 2015

[14] Dong-Jun Won; Seon-Ju Ahn; Il-Yop Chung; Seung-Il Moon, "A new algorithm to find the optimal numbers and locations of power quality monitors," Power Tech, 2005 IEEE Russia , vol., no., pp.1,7, 27-30 June 2005 doi: 10.1109/PTC.2005.4524389

[15] Polymeneas, E.; Benosman, M., "Finite time multi-agent coordination of distributed generation for grid reactive support," Innovative Smart Grid Technologies - Asia (ISGT Asia), 2014 IEEE , vol., no., pp.19,24, 20-23 May 2014 doi: 10.1109/ISGTAsia.2014.6873757

[16] Zhipeng Liu; Fushuan Wen; Ledwich, G., "Optimal Siting and Sizing of Distributed Generators in Distribution Systems Considering Uncertainties,"Power Delivery, IEEE Transactions on , vol.26, no.4, pp. 2541,2551, Oct. 2011 doi: 10.1109/TPWRD. 2011.2165972

[17] Nagarajan, A.; Ayyanar, R., "Dynamic analysis of distribution systems with high penetration of PV generators using differential algebraic equations in OpenDSS," North American Power Symposium (NAPS), 2014 , vol., no., pp.1,6, 7-9 Sept. 2014 doi: 10.1109/NAPS.2014.6965355

[18] Ramesh, L.; Chowdhury, S.P.; Chowdhury, S.; Song, Y.H.; Natarajan, A.A., "Voltage stability analysis and real power loss reduction in distributed distribution system," Transmission and Distribution Conference and Exposition, 2008. T\&D. IEEE/PES , vol., no., pp.1,6, 21-24 April 2008 doi: 10.1109/TDC.2008.4517070

[19] Opathella, C.; Singh, B.N.; Cheng, D.; Venkatesh, B., "Intelligent wind generator models for power flow studies in PSS®E and PSS®SINCAL," Power Systems, IEEE Transactions on , vol.28, no.2, pp.1149,1159, May 2013 doi: 10.1109/TPWRS.2012.2211043

[20] Opathella, C.; Venkatesh, B., "Intelligent Wind Generator models for power flow studies in PSS®E and PSS®SINCAL," Power and Energy Society General Meeting (PES), 2013 IEEE , vol., no., pp.1,1, 21-25 July 2013 doi: 10.1109/PESMG.2013.6672955 
[21] Malekpour, A.R.; Pahwa, A.; Natarajan, B., "Distributed volt/var control in unbalanced distribution systems with distributed generation," Computational Intelligence Applications in Smart Grid (CIASG), 2014 IEEE Symposium on , vol., no., pp.1,6, 9-12 Dec. 2014 doi: 10.1109/CIASG.2014.7011559

[22] Hoff, T.; Shugar, D.S., "The value of grid-support photovoltaics in reducing distribution system losses," Energy Conversion, IEEE Transactions on , vol.10, no.3, pp.569,576, Sep 1995 doi: $10.1109 / 60.464884$

[23] Ziari, I.; Ledwich, G.; Ghosh, A.; Cornforth, D.; Wishart, M., "Optimal allocation and sizing of DGs in distribution networks," Power and Energy Society General Meeting, 2010 IEEE, vol., no., pp.1,8, 25-29 July 2010 doi: 10.1109/PES.2010.5588114

[24] Iman Ziari, Gerard Ledwich, Arindam Ghosh, A new technique for optimal allocation and sizing of capacitors and setting of LTC, International Journal of Electrical Power \& Energy Systems, Volume 46, March 2013, Pages 250-257, ISSN 0142-0615, http://dx.doi.org/10.1016/j.ijepes.2012.09.010.

[25] Syafii; Nor, K.M.; Abdel-Akher, M., "Analysis of three phase distribution networks with distributed generation," Power and Energy Conference, 2008. PECon 2008. IEEE 2nd International , vol., no., pp.1563,1568, 1-3 Dec. 2008 doi: 10.1109/PECON.2008.4762730

[26] A.Y. Abdelaziz, Y.G. Hegazy, Walid El-Khattam, M.M. Othman, Optimal allocation of stochastically dependent renewable energy based distributed generators in unbalanced distribution networks, Electric Power Systems Research, Volume 119, February 2015, Pages 34-44, ISSN 0378-7796, http://dx.doi.org/10.1016/j.epsr.2014.09.005

[27] Hany E. Farag, E.F. El-Saadany, Ramadan El Shatshat, Aboelsood Zidan, A generalized power flow analysis for distribution systems with high penetration of distributed generation, Electric Power Systems Research, Volume 81, Issue 7, July 2011, Pages 14991506, ISSN 0378-7796, http://dx.doi.org/10.1016/j.epsr.201 03.001

[28] Naiem, A.F.; Hegazy, Y.; Abdelaziz, A.Y.; Elsharkawy, M.A., "A Classification Technique for Recloser-Fuse Coordination in Distribution Systems With Distributed Generation," Power Delivery, IEEE Transactions on , vol.27, no.1, pp.176,185, Jan. 2012 doi: 10.1109/TPWRD.2011.2170224.

[29] Baldwin, T.; Kelle, D.; Cordova, J.; Beneby, N., "," Power Systems Conference (PSC), 2014 Clemson University, vol., no., pp.1,8, 1114 March 2014 doi: 10.1109/PSC.2014.6808108

[30] De Oliveira-De Jesus, P.M.; Rojas Quintana, A.A., "Distribution System State Estimation Model Using a Reduced Quasi-Symmetric Impedance Matrix," Power Systems, IEEE Transactions on , vol.PP, no.99, pp.1,11 doi: 10.1109/TPWRS.2014.2374537

[31] Wencong Su, Jianhui Wang, Kuilin Zhang, Alex Q. Huang, Model predictive control-based power dispatch for distribution system considering plug-in electric vehicle uncertainty, Electric Power Systems Research, Volume 106, January 2014, Pages 29-35, ISSN 0378-7796, http://dx.doi.org/10.1016/j.epsr.2013.08.001.

[32] Garces, A.; Correa, C.A.; Bolanos, R., "Optimal operation of distributed energy storage units for minimizing energy losses," Transmission \& Distribution Conference and Exposition - Latin America (PES T\&D-LA), 2014 IEEE PES , vol., no., pp.1,6, 10-13 Sept. 2014 doi: 10.1109/TDC-LA.2014.6955220

[33] [Manbachi, M.; Farhangi, H.; Palizban, A.; Arzanpour, S., "Impact of $\mathrm{V} 2 \mathrm{G}$ on real-time adaptive Volt/VAr optimization of distribution networks," Electrical Power \& Energy Conference (EPEC), 2013 IEEE , vol., no., pp.1,6, 21-23 Aug. 2013 doi: 10.1109/EPEC.2013.6802909

[34] [32] Tanaka, H.; Tanaka, T.; Wakimoto, T.; Hiraki, E.; Okamoto, M., "Reduced-Capacity Smart Charger for Electric Vehicles on Single-Phase Three-Wire Distribution Feeders With Reactive Power Control," Industry Applications, IEEE Transactions on , vol.51, no.1, pp.315,324, Jan.-Feb. 2015 doi: 10.1109/TIA.2014.2327156

[35] Wencong Su; Jianhui Wang; Jaehyung Roh, "Stochastic Energy Scheduling in Microgrids With Intermittent Renewable Energy Resources," Smart Grid, IEEE Transactions on , vol.5, no.4, pp.1876,1883, July 2014 doi: 10.1109/TSG.2013.2280645

[36] Dall Anese, E.; Giannakis, G.B., "Convex distribution system reconfiguration using group sparsity," Power and Energy Society General Meeting (PES), 2013 IEEE , vol., no., pp.1,5, 21-25 July 2013 doi: 10.1109/PESMG.2013.6672702
[37] Juan Li; Xi-Yuan Ma; Chen-Ching Liu; Schneider, K.P., "Distribution System Restoration With Microgrids Using Spanning Tree Search," Power Systems, IEEE Transactions on , vol.29, no.6, pp.3021,3029, Nov. 2014 doi: 10.1109/TPWRS.2014.2312424

[38] Khushalani, S.; Solanki, J.M.; Schulz, N.N., "Development of Three-Phase Unbalanced Power Flow Using PV and PQ Models for Distributed Generation and Study of the Impact of DG Models," Power Systems, IEEE Transactions on , vol.22, no.3, pp.1019,1025, Aug. 2007 doi: 10.1109/TPWRS.2007.901476

[39] Dall Anese, E.; Giannakis, G.B., "Optimal distributed generation placement in distribution systems via semidefinite relaxation," Signals, Systems and Computers, 2013 Asilomar Conference on , vol., no., pp.369,373, 3-6 Nov. 2013 doi: 10.1109/ACSSC.2013.6810298

[40] R. Santhakumar, K. Kaliyaperumal," Mapping of Mobile Technology Publications: A Scientometric Approach", DESIDOC Journal of Library \& Information Technology, Vol. 34, No. 4, July 2014, pp. 298-303 DOI: 10.14429/djlit.34.5825. 